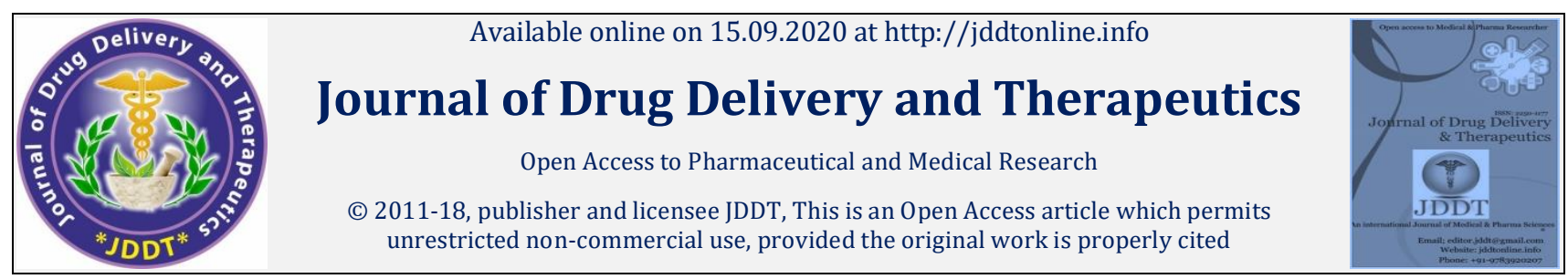

open 1 Access

Research Article

\title{
Formulation and Evaluation of Novel Formulation for Diabetes Induced Hypertension using Modified Innate Superdisintegrant
}

\author{
Pandit Vinay*, Kashive Dipanker, Sharma Tarun \\ Department of Pharmaceutics, Laureate Institute of Pharmacy, Kathog, H.P, India
}

\begin{abstract}
Objectives: Diabetes is a chronic disease and is a group of metabolic disorders characterized by high levels of sugar in blood (hyperglycemia). Hypertension is a major modifiable risk factor for cardiovascular morbidity and mortality in patients with diabetes. The objective of this research is to formulate Fast dissolving tablets of Pioglitazone and Cilnidipine for the effective treatment of diabetes induced hypertension.

Methods: Six formulations were prepared by direct compression technique by using Opuntia ficus-indica as an innate superdisintegrant.

Result and Discussion: All the formulations were subjected for precomprression, post compression parameters and shows all the data within the specific limits. F5 formulation with the mixture of polymers viz. Opuntia ficus indica, SSG, croscarmellose sodium, magnesium stearate, DiCOM showed comparatively fast disintegration and best release of drug than that of all other formulation. The tablets of F5 formulation disintegrated within 18.53 seconds can provide fast relief in the body. The in-vitro dissolution results revealed that the drug release of F5 formulation tablets was more than $90 \%$ for Pioglitazone and near to $70 \%$ for Cilnidipine within 30 minutes. Stability studies were performed on F5 formulation tablets showed no significant changes in color, disintegration time and in-vitro dissolution which showed that appearance of tablets was having no effect.
\end{abstract}

Conclusion: Fast dissolving tablets of Pioglitazone and Cilnidipine can be successfully prepared using direct compression technique and it will enhance the drug dissolution, which will further increase absorption and bioavailability of both drugs.

Keywords: Pioglitazone, Cilnidipine, diabetes induced hypertension, fast dissolving tablets, direct compression.

Article Info: Received 12 July 2020; Review Completed 27 August 2020; Accepted 06 Sep 2020; $\quad$ Available online 15 Sep 2020

Cite this article as:

Pandit V, Kashive D, Sharma T, Formulation and Evaluation of Novel Formulation for Diabetes Induced Hypertension using Modified Innate Superdisintegrant, Journal of Drug Delivery and Therapeutics. 2020; 10(5):240-250

http://dx.doi.org/10.22270/jddt.v10i5.4412

*Address for Correspondence:

Dr. Vinay Pandit, Professor \& Head, Department of Pharmaceutics, Laureate Institute of Pharmacy, Kathog, H.P, India

\section{INTRODUCTION}

Diabetes is a chronic disease and is a group of metabolic disorders characterized by high levels of sugar in blood (hyperglycemia). Untreated high blood sugar from diabetes can damage nerves, eyes, kidneys, and other organs. Over 30 million have now been diagnosed with diabetes in India. The CPR (Crude prevalence rate) in the urban areas of India is thought to be 9 per cent. In rural areas, the prevalence is approximately 3 per cent of the total population. The prevalence of diabetes in Himachal Pradesh is about 14\%.

About $90 \%$ of people with diabetes have type 2 diabetes mellitus. This chronic condition develops when $\beta$-cells fail to secrete sufficient insulin to keep up with demand, usually in the context of increased insulin resistance. The most acute complications of uncontrolled type 2 Diabetes Mellitus which could be threatening to the life is the hyperglycemia accompanied with ketoacidosis (body produces excess blood acids) or high blood pressure. ${ }^{1}$

Hypertension is a condition that's seen in people with type 2 diabetes. Hypertension and diabetes are two of the leading risk factors for atherosclerosis and its complications, including heart attacks and strokes. There is substantial overlap between diabetes and hypertension, reflecting substantial overlap in their etiology and disease mechanisms, therefore, this condition can be known as diabetes induced hypertension (DIH). Northern region of India has shown highest prevalence of DIH with $18.83 \%{ }^{2,3}$

Pioglitazone is one of drug of choice belonging to thiazolidinediones uses in glycemic control by lowering insulin resistance. Thiazolidinediones (TZDs), a peroxisome proliferator-activated receptor $\gamma$ activators works by improving the insulin sensitivity in adipocytes, cardiac muscles and the liver. TZDs acts by activating PPAR (a group 
of nuclear receptors), specifically PPAR $\gamma$ and PPAR $\alpha$ on the small extent which works on $\beta$-cells to preserve the secretion of insulin. ${ }^{4}$ Pioglitazone also has beneficial effects on lipid metabolism and cardiovascular risk. In contrast Cilnidipine, a long acting fourth generation dihydropyridine calcium antagonist improves insulin resistance along with management of hypertension. Cilnidipine inhibits both $\mathrm{L} / \mathrm{N}$ types of calcium channels more potently than other conventional CCBs. ${ }^{5}$

Fast dissolving tablets FDTs or orodispersible tablets are novel system that dissolves, disintegrate the drug in saliva within few seconds with or without intake of water. FDTs are predicted to promote higher drug dissolution/absorption as well as rapid onset of pharmacological action and/or higher drug bioavailability, compared to conventional dosage forms. Generally superdisintegrants viz., sodium starch glycolate, croscarmellose sodium and herbal extracts are used for the formulation of FDTs. The innate excipients play an important role not only in disintegration of tablets but also have pharmacodynamic actions in the formulations. These pharmacodynamic actions are generally synergistic.6, 7

Addition of superdisintegrants is the basic approach that plays a vital role in the dissolution and disintegration of fast dissolving tablets. Opuntia ficus-indica commonly known as Cactus fruit or nopal traditionally used as an alternative treatment for diabetes and hypertension. Opuntia ficusindica shows hypoglycemic effect by enhancing peripheral glucose uptake through activation of AMPK/p38 MAPK (mitogen-activated protein kinase) pathway ${ }^{8}$. Opuntia ficusindica also inhibits alpha-glucosidase activity and intestinal glucose absorption. Therefore, mucilage of Opuntia ficus indica can be used as innate superdisintegrant not only for its formulation utility but also for its pharmacodynamic action ${ }^{9}$. Thus, it was hypothesized that combination of antidiabetic i.e. Pioglitazone and anti-hypertensive i.e. Cilnidipine with Opuntia ficus indica would be more effective in the treatment of diabetes induced hypertension. Hence, the aim of our research work was to formulate, develop and evaluate combinational therapy containing Pioglitazone and cilnidipine for the management of diabetic induced hypertension using Opuntia ficus-indica extract as innate superdisintegrant.

\section{MATERIALS AND METHODS}

Pioglitazone was obtained as gift sample from Cipla Limited, India. Cilnidipine was obtained as gift sample from Lark laboratories, India. Sodium starch glycolate and Croscarmellose sodium was obtained as gift sample from Yarrow Chem Products. Microcrystalline cellulose, sodium hydroxide, potassium dihydrogen phosphate and Disodium hydrogen ortho phosphate were obtained from Central Drug House Private Limited, India. Magnesium stearate was obtained as gift sample from Spectrochem Private Limited, India and all other chemicals/solvents used were of analytical grade.

\section{Preformulation Studies}

All the Preformulation studies like physical characterization, melting point, solubility study, partition coefficient, differential scanning calorimetry were carried out effectively.

\section{Physical characterization}

The drug was physically characterized on the basis of color, odour and physical state. All the physical parameters were recorded and compared with the literature.

\section{Determination of Melting point}

The melting point of Pioglitazone and Cilnidipine was obtained by using the Digital melting point apparatus. A small quantity of the drug was filled in the capillary tube with one end closed and placed in the melting point apparatus. Then, the melting point was recorded of the following drugs.

Determination of wavelength of maximum absorption ( $\lambda$ max) and preparation of calibration curve ${ }^{10-13}$

\section{Determination of in $\lambda \max 0.1 \mathrm{~N} \mathrm{HCl}$}

The absorption maxima ( $\lambda$ max) of Pioglitazone and Cilnidipine were determined in $0.1 \mathrm{~N} \mathrm{HCl}$ by scanning the drug in the range 400-200 $\mathrm{nm}$ using UV-spectrophotometer.

\section{Preparation of stock solution}

Pioglitazone and Cilnidipine $100 \mathrm{mg}$ of drug was weighed accurately and transferred to $100 \mathrm{ml}$ volumetric flask and a small quantity of $0.1 \mathrm{~N}$ HCL solvent was added and the drug was allowed to dissolve (with help of sonication) and volume was made up to mark with $0.1 \mathrm{~N} \mathrm{HCl}$ to obtain $1000 \mu \mathrm{g} / \mathrm{ml}$ concentration. From this solution, $10 \mathrm{ml}$ was withdrawn and transferred to the volumetric flask and makeup to $100 \mathrm{ml}$ to obtain $100 \mu \mathrm{g} / \mathrm{ml}$ concentrations. This solution was known as a stock solution.

\section{Preparation of Calibration curve in $0.1 \mathrm{~N} \mathrm{HCl}$}

From the stock solution serial dilution or aliquots of $0.2,0.4$, $0.6,0.8,1.0,1.2 \mathrm{ml}$ of $100 \mu \mathrm{g} / \mathrm{ml}$ of both drugs was pipetted from stock solution into each of six $10 \mathrm{ml}$ of volumetric flask. The volume was made up to $10 \mathrm{ml}$ with $0.1 \mathrm{~N} \mathrm{HCl}$. Absorbance was measured at $221 \mathrm{~nm}$ for Pioglitazone and $224 \mathrm{~nm}$ for Cilnidipine against similarly treated blank using UV-spectrophotometer using similarly treated blank.

\section{Determination of drug solubility}

Pioglitazone and Cilnidipine were tested for solubility in water, $0.1 \mathrm{~N} \mathrm{HCL}$, methanol, and phosphate buffer (6.8) using Higuchi Connor's method. In brief, the sufficient amount (in excess) of the drug was taken in thoroughly cleaned and dried volumetric flask $(25 \mathrm{ml})$. Different investigate solvents mentioned above were added up to mark, closed tightly, and then placed in shaking water bath incubator at $30^{\circ} \mathrm{c}$. These flasks were then observed at definite time intervals for undissolved drug particles; if the drug gets solubilized then more quantity of the drug was added with continuous shaking. Further, the shaking was continued for the next 48 hours after the last time of drug added. Samples were then filtered and measured at $221 \mathrm{~nm}$ for Pioglitazone and at $224 \mathrm{~nm}$ for Cilnidipine using a UV spectrophotometer using a similarly treated blank.

\section{Determination of Partition Coefficient}

To know the level of partitioning behavior in the lipophilic and hydrophilic environment, drug partitioning study was performed. The partition coefficient of the drug or formulation is the aqueous or non-aqueous system was determined by the Shake flask method. Distilled water was chosen as aqueous phase and n-Octanol was used as a nonaqueous phase to maintain the drug in unionized form. In brief, $10 \mathrm{ml}$ of n-octanol and $10 \mathrm{ml}$ of distilled water was added in separating funnel and shaken for 30 minutes (without drug) in a separating funnel for the pre-saturation of both phases. Then, drug $(10 \mathrm{mg})$ was added to the mixture and shaken for $3 \mathrm{hrs}$. The final mixture was kept for 1 hour to separate two layers (the aqueous layer and oily layer). Pipette out $1 \mathrm{ml}$ from the aqueous layer and transferred to $10 \mathrm{ml}$ of volumetric flask and volume was made up to $10 \mathrm{ml}$ 
with $0.1 \mathrm{~N} \mathrm{HCl}$ and analyzed at $221 \mathrm{~nm}$ for Pioglitazone and $224 \mathrm{~nm}$ for Cilnidipine against similarly treated blank using UV- spectrophotometer.

From the oil layer, a $1 \mathrm{ml}$ sample was taken and kept for 6-7 hours at room temperature. After evaporation, the remaining solution was diluted with $0.1 \mathrm{~N} \mathrm{HCl}$ up to 10 $\mathrm{ml}$ and the concentration of solute was analyzed against similarly treated blank using UV-spectrophotometer. The partition coefficient was calculated using the following formula.

Partition coefficient $=\frac{\text { Concentration of drug in the organic phase }}{\text { Concentration of drug in the aqueous phase }}$

\section{Fourier transformer infrared spectroscopy (FT-IR)}

The compound was estimated by FTIR to determine the functional groups of Pioglitazone $\mathrm{HCl}$ and Cilnidipine. It was studied by the FTIR spectrophotometer (Shimadzu IR Affinity-1).The spectrum was obtained using the Press pellet technique. The mixture of drug and potassium bromide $(\mathrm{KBr})$ was ground into fine powder in the ratio of 1:100 using a mortar pestle and then compressed into $\mathrm{KBr}$ disc by applying the pressure of 10 ton for 1 minute for both the drugs individually. The pellets were transferred to the sample holder and placed in the spectrophotometer and scanned at 4000 to $400 \mathrm{~cm}^{-1}$ at a resolution of $4 \mathrm{~cm}^{-1}$ and interpretation of spectrum was further done ${ }^{14}$.

\section{Drug-drug compatibility study}

A mixture of Pioglitazone and Cilnidipine was prepared and their spectrum was obtained by using the $\mathrm{KBr}$ press pellet technique. Pellet was prepared by mixing the drugs and $\mathrm{KBr}$ in the ratio of 1:100 and applying the pressure of 10 tons for 1 minute. The sample disc was prepared and placed in the sample holder and was scanned at 4000 to $400 \mathrm{~cm}^{-1}$ and the interpretation of the spectrum was further done by comparing the spectrum with a spectrum of the individual drug.

\section{Drug excipients compatibility study}

The compatibility study of Pioglitazone and Cilnidipine was done by using the mixture of different excipients viz, sodium starch glycolate, cross carmellose, magnesium stearate, DiCOM, and Opuntia ficus-indica. The infrared spectrum of the physical mixture of excipients was developed in pure form by using $\mathrm{KBr}$ pellet technique taking excipients and $\mathrm{KBr}$ in the ratio 1:100. The pressure of 10 ton was applied in $\mathrm{KBr}$ press for one minute. The pellets were then transferred to the sample holder and placed in an FT-IR spectrophotometer and scanned at a wavelength of 4000 to $400 \mathrm{~cm}^{-1}$ at a resolution of $2 \mathrm{~cm}^{-1}$. Similarly, the spectrum of the herbal extract i.e. Opuntia ficus-indica with both the drugs Pioglitazone and Cilnidipine was developed and the interpretation of spectrum was further done ${ }^{15}$.

\section{Differential scanning calorimetry (DSC studies)}

Differential scanning calorimetry or DSC is a thermo analytical technique in which the difference in the amount of heat required to increase the temperature of a sample and reference is measured as a function of temperature. The sample Opuntia ficus-indica was studied in Differential scanning calorimetry. $4 \mathrm{mg}$ of sample was taken and was heated under nitrogen atmosphere in hermetically sealed aluminum pans over a temperature range $20^{\circ} \mathrm{C}$ to $600^{\circ} \mathrm{C}$ under $\mathrm{N}_{2}$ flow rate of $50 \mathrm{ml} / \mathrm{min}$.

\section{Formulation development}

\section{Extraction of Opuntia ficus-indica mucilage}

Collection: The fruits of fresh Opuntia ficus-indica were collected from the hilly areas of Himachal Pradesh in the month of November for the extraction of mucilage. The fruits were washed well with water. The fruits were opened and seeds were removed properly.

Extraction: The fruits were crushed and soaked in water for 5-6 hours, boiled for 30 minutes and left to stand for 1 hour to allow complete release of the mucilage in to the water. The mucilage was extracted using multi-layer muslin cloth bag to remove the marc from the solution. Acetone (in the volumes of three times to the volume of filtrate) was added to precipitate the mucilage.

The mucilage was separated, dried in an oven at $40^{\circ} \mathrm{C}$, collected, grounded and passed through a \#80 sieve and stored in desiccator at $30^{\circ} \mathrm{c}$ and $45 \%$ relative humidity till use in formulation of fast dissolving tablets ${ }^{16}$.

\section{Preparations of powder blend by direct compression} method

Fast dissolving tablets will be prepared by direct compression technique using different polymers with varying concentrations. The drug and polymers (Sodium starch glycolate, croscarmellose sodium, magnesium stearate, DiCOM) were mixed compressed. The direct compression method is the most easy and suitable method used by various formulation scientists for different formulations.

In this method after collecting the raw materials, all ingredients weighed according to the formulation code and their decreasing order to make a blend and all ingredients passed through sieve \#60. Blending was carried out by employing the trituration method independently. Trituration was carried out in mortar and pestle. Powders were blended for $10 \mathrm{~min}$ to $15 \mathrm{~min}$, respectively, in each trial by trituration. After blending it was analyzed for the organoleptic properties and micromeritics properties ${ }^{17}$.

Table 1: Formulation chart for fast dissolving tablets of Pioglitazone and Cilnidipine (Direct compression method)

\begin{tabular}{|c|c|c|c|c|c|c|c|}
\hline S.No. & Ingredients & $\begin{array}{c}\text { F1 } \\
\text { (mg) }\end{array}$ & $\begin{array}{c}\text { F2 } \\
\text { (mg) }\end{array}$ & $\begin{array}{c}\text { F3 } \\
(\mathbf{m g})\end{array}$ & $\begin{array}{c}\text { F4 } \\
\text { (mg) }\end{array}$ & $\begin{array}{c}\text { F5 } \\
\text { (mg) }\end{array}$ & $\begin{array}{c}\text { F6 } \\
\text { (mg) }\end{array}$ \\
\hline 1. & Pioglitazone & 45 & 45 & 45 & 45 & 45 & 45 \\
\hline 2. & Cilnidipine & 15 & 15 & 15 & 15 & 15 & 15 \\
\hline 3. & Opuntia ficus-indica & 8.5 & 8.5 & 8.5 & 5 & 5 & - \\
\hline 4. & Sodium starch glycolate & 15 & 15 & 15 & 15 & 15 & 15 \\
\hline 5. & Croscarmellose sodium & 5 & 8.5 & 15 & - & 5 & 5 \\
\hline 6. & Magnesium stearate & 2 & 2 & 2 & 1 & 1 & 1 \\
\hline 7. & DiCOM & 79.5 & 76 & 69.5 & - & 84 & 89 \\
\hline 8. & MCC & - & - & - & 89 & - & - \\
\hline & Total quantity & 170 & 170 & 170 & 170 & 170 & 170 \\
\hline
\end{tabular}




\section{Pre-Compression Studies}

Pre-compression studies like bulk density, tapped density, Carr's index, Hausner's ratio, angle of repose, percentage porosity were carried out successfully ${ }^{18-19}$.

\section{Compression of fast dissolving tablets by direct compression method}

Fast dissolving tablets containing Pioglitazone and Cilnidipine and herbal extract (Opuntia ficus-indica) were prepared by direct compression method. The ingredients mentioned in formulation code in Table 1 were weighed accurately and mixed by trituation in a mortar and pestle for 15-20 minutes. All the ingredients were screened through sieve no.60. The prepared blend of the formulation was pre compressed, on 10-station rotary tablet punching machine at a low compression force to form round flat-faced shaped tablet of $9 \mathrm{~mm}$ punch diameter. Then, half quantity of DiCOM and minute quantity of Magnesium stearate was used to prevent the bidirectional flow or friction and to provide lubrication and final compression was done at a high compression force. After compression of tablets, the upper punch was removed carefully without disturbing the set up and mixed ingredients. After the completion of the tablet compression, the prepared tablets were taken to evaluation for the post compression studies.

\section{Post compression studies}

The prepared tablets were evaluated for the post compression studies which are as follows ${ }^{20-22:}$

\section{General appearance}

General appearance of a tablet, its visual identity and overall elegance is essential for the patient acceptance. The tablet's size, shape, color, presence or absence of odor, legibility of any identifying marking was studied as the general appearance characteristic.

\section{Hardness}

Hardness indicates the ability of a tablet to withstand mechanical shocks while handling. The hardness of the tablets was determined using Monsanto hardness tester. It is expressed in $\mathrm{kg} / \mathrm{cm}^{2}$. The tablet was held between the moving jaw and the screw knob was moved upward until the tablet breaks and force required to break the tablet was noted. Three tablets were randomly picked and hardness of the same tablets from the formulation was determined. The mean and standard deviation values were also calculated. Usually, the range of hardness for FDTs should be 2-3 $\mathrm{kg} / \mathrm{cm}^{2}$.

\section{Thickness}

The thickness of pre-weighed 10 tablets of the formulation was measured using Digital vernier caliper. The thickness was measured by placing tablets between two arms of the vernier caliper. The determination of thickness was done for 10 tablets.

\section{Diameter}

The diameter of pre-weighed 10 tablets is determined by using Digital vernier caliper. The diameter was measured by placing tablets between the two arms of the vernier caliper and the determination was done for 10 tablets for each formulation.

\section{Friability}

Friability is the loss of tablet mass in the container due to removal of fine particles from the surface during transportation and handling. The friability of tablets were determined using Roche Friabilator (USP tablet friabilator EF-2, electro lab, Mumbai). It is expressed in percentage (\%). Ten tablets were initially weighed (Winitial) and transferred into friabilator. The friabilator was operated at $25 \mathrm{rpm}$ for 4 minutes or run up to 100 revolutions. The tablets were weighed again (Wfinal). The $\%$ friability was then calculated by,

$$
F=\frac{\text { Initial weight }- \text { final weight }}{\text { Initial weight }} \times 100
$$

$\%$ Friability of tablets less than $1 \%$ are considered acceptable.

\section{Weight variation}

Randomly, 20 tablets were selected from the formulation and weighed individually. Average weight was calculated and comparison was made between individual and average weights of the tablets.

\section{Determination of drug content}

10 tablets from each batch were crush and mass equivalent to one tablet was taken in a $100 \mathrm{ml}$ volumetric flask, mass equivalent to one tablet was taken and volume was made to mark with $0.1 \mathrm{~N}$ HCL. The flask was shaken thoroughly using a water bath shaker incubator. The solution was filter and analyzed after suitable dilutions using UV- visible spectrophotometer.

\section{In vitro disintegration time}

The process of breakdown of a tablet into smaller particles is called as disintegration. The in-vitro disintegration time of a tablet was determined using disintegrant test apparatus as per I.P specifications. Place one tablet in each of the 6 tubes of the basket. Add a disc to each tube and run the apparatus using $0.1 \mathrm{~N} \mathrm{HCl}$ maintained at $37 \pm 2^{\circ} \mathrm{C}$ as the immersion liquid or solvent. The assembly should be raised and lowered between 30 cycles per minute in the $0.1 \mathrm{~N} \mathrm{HCl}$ maintained at $37 \pm 2^{\circ} \mathrm{c}$. The time in seconds taken for complete disintegration of the tablet with no palpable mass remaining in the apparatus was measured and recorded.

\section{In vitro dissolution studies}

Dissolution is the process of extracting the API out of the dosage form solid state matrix into solution within gastrointestinal tract. Dissolution testing is an in vitro method that characterizes how an API is extracted out of a solid dosage form. Dissolution rate was studied by using USP type-II apparatus (DS 8000 Labindia, India) using $900 \mathrm{ml}$ of $0.1 \mathrm{~N} \mathrm{HCl}$ as dissolution medium. Temperature of the dissolution medium was maintained at $37 \pm 0.5^{\circ} \mathrm{c}$, samples of $5 \mathrm{ml}$ from dissolution medium were withdrawn at predetermined time intervals and replaced with fresh medium. Samples were filtered through $0.45 \mu \mathrm{m}$ membrane filter disc (Millipore Corporation) and analyzed after appropriate dilution by measuring the absorbance at 221 $\mathrm{nm}$ and $224 \mathrm{~nm}$.

\section{Mathematical models for drug release studies}

Mathematical models for the drug release studies play a significant role as it establishes a mechanism of drug release and provides more general guidelines for the development of the other systems ${ }^{23-24}$.

a) Zero order kinetics model: Zero-order release kinetics describe systems where drug release rate is constant over a period of time. Drug dissolution from dosage forms that do not disaggregate and release the drug slowly can be represented by the equation: 


$$
\mathrm{Q}_{\mathrm{t}}=\mathrm{Q}_{0}+\mathrm{K}_{0} \mathrm{t}
$$

Where, $Q_{t}$ is the amount of drug dissolved in time $t$,

$\mathrm{Q}_{0}$ is the initial amount of drug in the solution (most times, $\mathrm{Q}_{0}=0$ ) and

$\mathrm{K}_{0}$ is the zero order release constant expressed in units of concentration/time.

$\mathrm{T}_{\mathrm{o}}$ study the release kinetics, data obtained from in vitro drug release studies were plotted as cumulative amount of drug released versus time.

b) First order kinetics model: The release of the drug which followed first order kinetics can be expressed by the equation:

$$
\log \mathrm{C}=\log \mathrm{C}_{0}-\mathrm{Kt} / 2.303
$$

Where, $\mathrm{C}_{0}$ is the initial concentration of drug, $\mathrm{k}$ is the first order rate constant, and $t$ is the time. The data obtained are plotted as log cumulative percent-age of drug remaining vs. time which would yield a straight line with a slope of $\mathrm{K} / 2.303$.

c) Higuchi model: It is a mathematical model aimed to describe drug release from a matrix system. In a general way, Higuchi model is expressed as;

$$
\mathrm{f}_{\mathrm{t}}=\mathrm{Q}=\mathrm{KH} \times \mathrm{t}_{1 / 2}
$$

Where, $\mathrm{KH}$ is the Higuchi dissolution constant.

The data obtained were plotted as cumulative percentage drug release versus square root of time.

d) Weibull model: This model has been described for different dissolution processes as the equation;

$$
\mathrm{M}=\mathrm{M}_{0}\left(1-\mathrm{e}^{-\mathrm{k}(\mathrm{t}-\mathrm{T}) \mathrm{b} / \mathrm{a}}\right)
$$

Where,

$M$ is the amount of drug dissolved as function of time, $M_{0}$ is the total amount of drug being released.

a denotes a scale parameter that describes the time dependence, $b$ describes the shape of dissolution curve progression

The Weibull model is more useful for comparing the release profiles of matrix type drug delivery. To study the drug release kinetics, data obtained were plotted as log cumulative percentage release of the drug versus log time.

e) Korsmeyer-Peppas model: Korsmeyer et al. derived a simple relationship which described drug release from a polymeric system equation; $\mathrm{Mt} / \mathrm{M} \infty=\mathrm{Ktn}$

Where Mt/ Mo is a fraction of drug released at time $t, k$ is the release rate constant and $\mathrm{n}$ is the release exponent. The $\mathrm{n}$ value is used to characterize different release for cylindrical shaped matrices.

To study the release kinetics, data obtained from in vitro drug release studies were plotted as log cumulative percentage drug release versus log time.

\section{Stability studies}

The fast dissolving tablets stored under the suitable conditions for a period as prescribed by ICH guidelines for accelerated studies. The optimized final formulation F5 was subjected to stability studies for 2 months. The formulation was kept in stability chamber at temperature $40 \pm 1^{\circ} \mathrm{C}$ and Relative humidity $75 \% \pm 5 \%$. After 2 months, the formulation was subjected to general appearance, friability, hardness, In vitro disintegration and In vitro dissolution studies etc ${ }^{25}$.

\section{RESULT AND DISCUSSION}

\section{Preformulation parameters}

Pioglitazone and Cilnidipine were observed for organoleptic properties and both were having white solid crystalline appearance. Both the drugs were odorless, confirming to the literature available. The melting point of Pioglitazone was found to be $180^{\circ} \mathrm{C} \pm 0.5$ and Cilnidipine was found to be 117 $\pm 0.03^{\circ} \mathrm{C}$ which confirms the literature values. The melting point indicates the purity of drugs.

\section{Determination of wavelength of maximum absorption ( $\lambda$ max) and preparation of calibration curve}

Determination of maximum absorption was done using $0.1 \mathrm{~N}$ $\mathrm{HCl}$ as solvent, for Pioglitazone solution of $12 \mu \mathrm{g} / \mathrm{ml}$ concentration and for Cilnidipine solution of $10 \mu \mathrm{g} / \mathrm{ml}$ was used.

The spectrum was obtained at $221 \mathrm{~nm}$ and $224 \mathrm{~nm}$ by scanning the wavelength range of $400-200 \mathrm{~nm}$ for Pioglitazone and Cilnidipine respectively as shown in Figure 1.
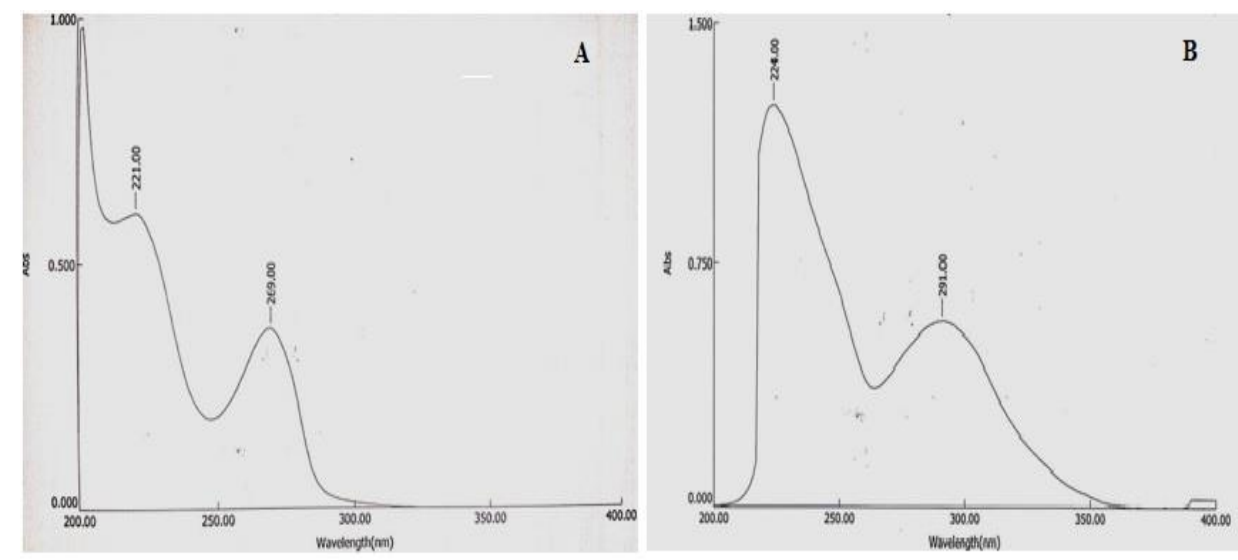

Figure 1: UV- visible spectrophotometer scan spectrum of A) Pioglitazone B) Cilnidipine 


\section{Preparation of Calibration Curve}

The calibration curve for pioglitazone and cilnidipine was prepared at $\lambda$ max of $221 \mathrm{~nm}$ and $224 \mathrm{~nm}$ respectively. The calibration curve for pioglitazone showed $\mathrm{R}^{2}$ value of 0.998 having slope of 0.054 , and intercept 0.003 whereas for Cilnidipine, $\mathrm{R}^{2}$ was found to be 0.998 , with slope of line of 0.073 , and intercept was found to be 0.023 . The calibration curve of Pioglitazone and Cilnidipine are shown in Figure 2.

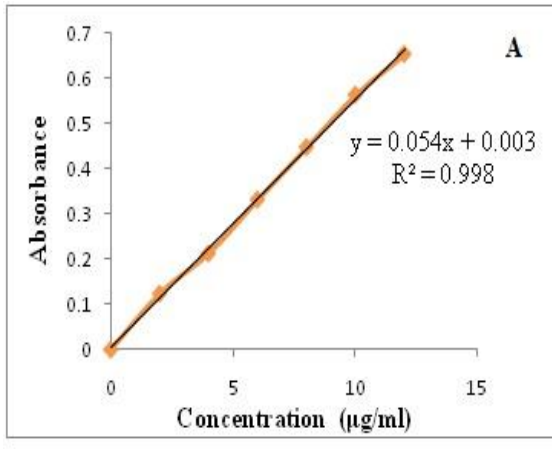

Figure 2: Calibration curve for A) Pioglitazone

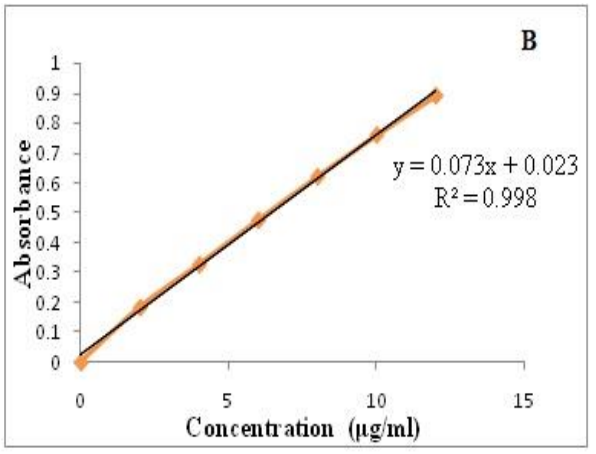

B) Cilnidipine

\section{Solubility determination}

The solubility study of Pioglitazone and Cilnidipine was done in various solvents (Figure 3). Pioglitazone and Cilnidipine were found to be freely soluble in methanol.

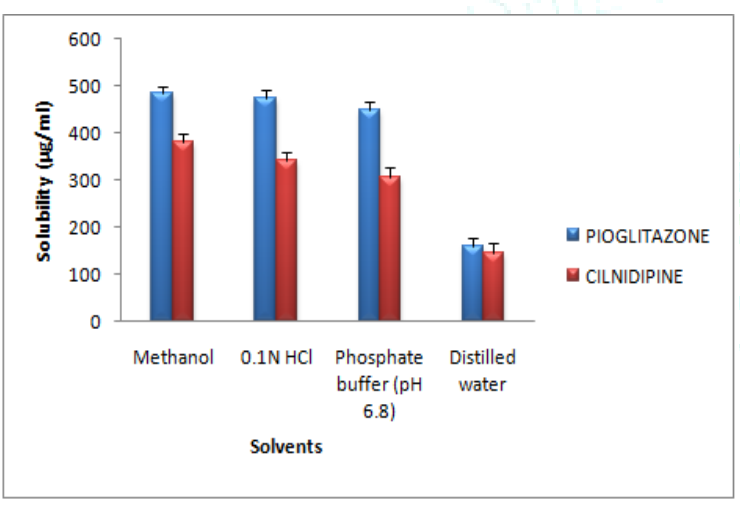

Figure3: Solubility study of Pioglitazone and Cilnidipine in various solvents
While Pioglitazone and Cilnidipine, both were found to be soluble in $0.1 \mathrm{~N} \mathrm{HCl}$. The selection of $0.1 \mathrm{~N} \mathrm{HCl}$ was done as solvent for the UV-visible spectrophotometer method validation because for better solubility.

\section{Determination of partition coefficient}

The determination of the partition coefficient of Pioglitazone and Cilnidipine was done with the mixture of n- octanol and distilled water. The partition coefficient $(\log \mathrm{P})$ value for Pioglitazone was found to be $2.70 \pm 0.02$, while for Cilnidipine it was found to be $4.88 \pm 0.1$. The Cilnidipine was found to be more lipophilic than Pioglitazone.

\section{Fourier transform infrared spectroscopy (FT-IR)}

Compound was estimated by FTIR to determine the functional groups of Pioglitazone and Cilnidipine. It was studied by FTIR spectrophotometer (Shimadzu IR Affinity-1). The infrared spectrum of Pioglitazone and Cilnidipine was obtained with the help of FT-IR spectrophotometer, using $\mathrm{KBr}$ pellet technique. The FT-IR of Pioglitazone is shown in table 2 and Figure 4.

Table 2: Interpretation of FT-IR spectrum of Pioglitazone

\begin{tabular}{|c|c|c|}
\hline Functional groups & Reported value(cm $\mathbf{- 1})$ & Observed value(cm-1) \\
\hline Aromatic $1^{\circ}$ amine (N-H stretch) & $3509-3460$ & 3675.52 \\
\hline Carbonyl group(C=0) cyclic & $1745-1680$ & 1683.93 \\
\hline Ether (C-O-C) & $1250-1150$ & 1182.41 \\
\hline Sulphonamides (S-NH) & $1169-1152$ & 1157.34 \\
\hline
\end{tabular}

The FT-IR of Cilnidipine is shown in Figure.4 and the interpretation of FT-IR spectrum of Cilnidipine is shown in Table 6 \& Figure 4, which also confirms the identity of Cilnidipine.

Table 6: Interpretation of FT-IR spectrum of Cilnidipine

\begin{tabular}{|c|c|c|}
\hline Functional groups & Reported value(cm-1) & Observed value(cm-1) \\
\hline Aromatic $2^{\circ}$ amine (N-H stretching) & $3320-3270$ & $3310.95 \mathrm{~cm}^{-1}$ \\
\hline Alkenes (C=C stretching acyclic) & $1680-1625$ & 1682.00 \\
\hline Nitroso (N=0) & $1290-1190$ & 1251.00 \\
\hline Nitro(-N-O) & $1357-1318$ & 1332.87 \\
\hline Methoxy(-ОСН3) & $2830-2810$ & 2828.23 \\
\hline
\end{tabular}




\section{Drug- drug / excipient compatibility study}

The compatibility study of Pioglitazone and Cilnidipine was done by physical evaluation and infrared spectrum. The physical evaluation of mixture of Pioglitazone and Cilnidipine was done by observing color and odor. There was no change in color of mixture and there was no evaluation of any odor.

The FT-IR spectrum of mixture is shown in Figure 4. The comparison of FT-IR of mixture of Pioglitazone and Cilnidipine was done with individual spectrum of Pioglitazone and Cilnidipine . No interaction was observed and as all of the important peaks of individual drugs were present in the spectrum of mixture and both the drugs are compatible and formulation can be developed for the combination of Pioglitazone and Cilnidipine.

Further, infrared spectrum of Pioglitazone and Cilnidipine with the Opuntia ficus-indica (herbal extract) was carried out using a mixture of both drugs with herbal extract and $\mathrm{KBr}$ in the ratio 1:100. FT-IR spectrum of Pioglitazone and Cilnidipine with herbal extract (superdisintegrant) is shown in Figure 4. Similarly, FT-IR spectrum of physical mixture of excipients was also carried out and shown in Figure 4. There was no change in the major peaks of the drugs used either with herbal extract or with excipients used. Therefore, it was inferred that herbal extract and selected excipients can be used in the development of fast dissolving tablet of Pioglitazone and Cilnidipine.
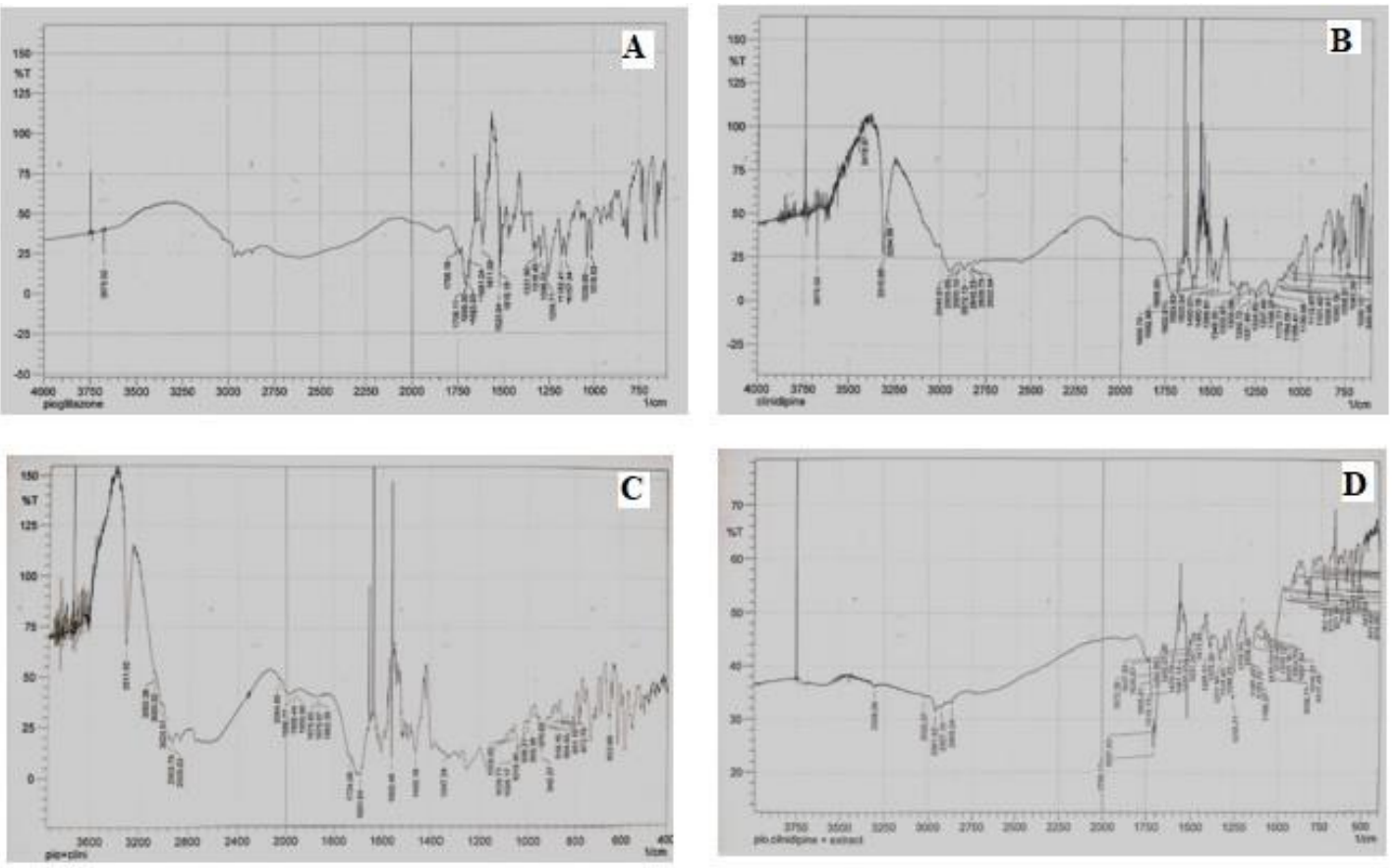

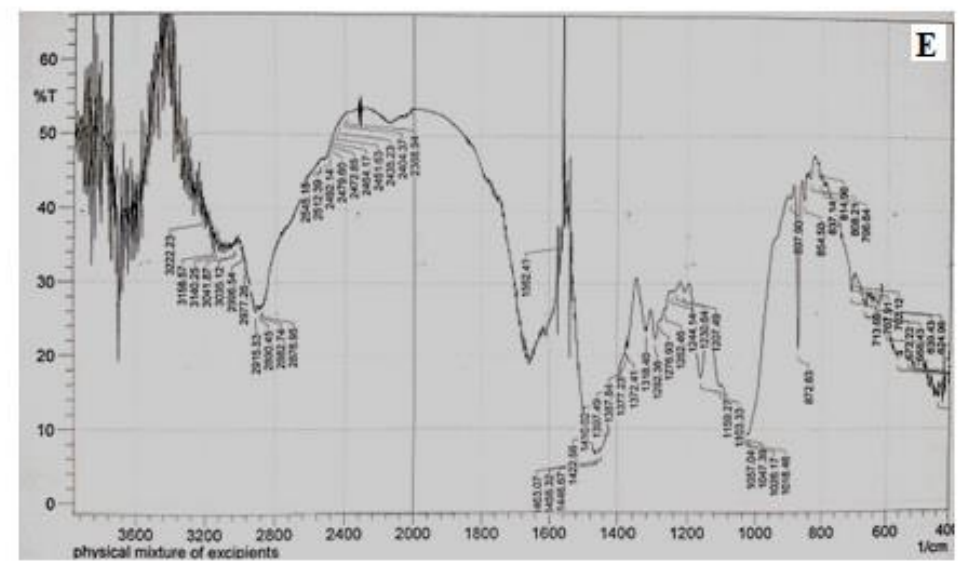

Figure 4: FT-IR spectrum of A) Pioglitazone B) Cilnidipine C) Pioglitazone and Cilnidipine D) Herbal extract with Pioglitazone and Cilnidipine E) Physical mixture of excipients

\section{Differential scanning calorimetry}

The DSC curve for an extract (Figure 5) of Opuntia ficusindica has an endothermic event with a peak near $243^{\circ} \mathrm{C}$ is observed, indicating the melting of extract. Earlier to this endothermic peak, an exothermic peak at $65^{\circ} \mathrm{C}$ was observed which may be attributed due to little moisture present in the extract. A sharp exothermic peak was observed at $490^{\circ} \mathrm{C}$ indicating the crystallization of the extract. 


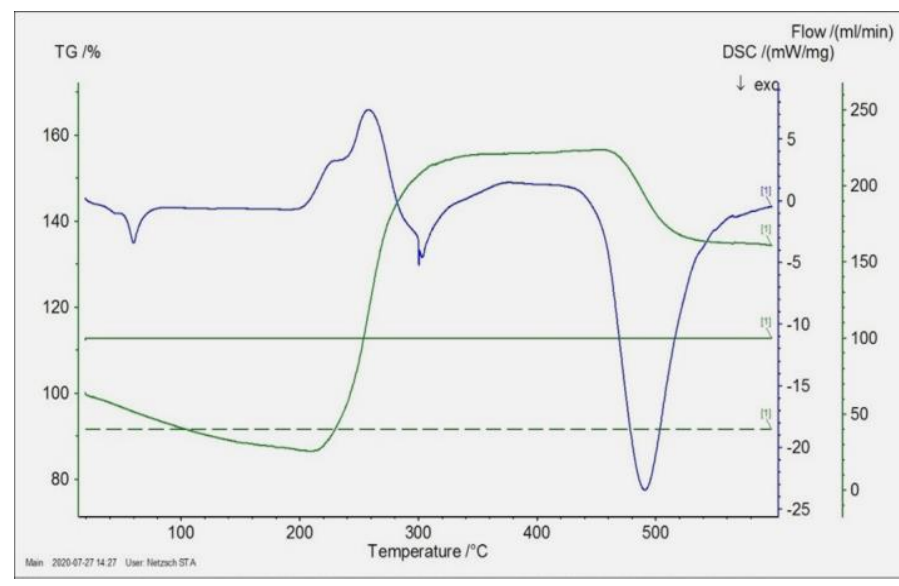

Figure 5: DSC curve for herbal extract (Opuntia ficus-indica)

\section{Pre-compression parameters}

The values of pre-compression parameters evaluated were found to be within the prescribed limits and data are tabulated in Table 7. The bulk density for all the formulations ranged from $0.799 \pm 0.001$ to $0.853 \pm 0.002$ indicating proper packaging of powder in the die cavity. The flow properties of all powders were found to be good as indicated by Hausner's ratio and angle of repose.

Table 7: Pre-compression studies of various formulations

\begin{tabular}{|c|c|c|c|c|c|c|}
\hline \multirow[b]{2}{*}{ Parameters } & \multicolumn{6}{|c|}{ Formulation code } \\
\hline & F1 & F2 & F3 & F4 & F5 & F6 \\
\hline Bulk density (g/ml) & $0.812 \pm 0.002$ & $0.823 \pm 0.002$ & $0.799 \pm 0.001$ & $0.834 \pm 0.004$ & $0.853 \pm 0.002$ & $0.813 \pm 0.001$ \\
\hline $\begin{array}{c}\text { Tapped } \\
\text { density }(\mathrm{g} / \mathrm{ml})\end{array}$ & $0.936 \pm 0.002$ & $0.928 \pm 0.002$ & $0.919 \pm 0.002$ & $0.917 \pm 0.002$ & $0.971 \pm 0.002$ & $0.937 \pm 0.002$ \\
\hline Carr's index (\%) & $13.64 \pm 0.379$ & $11.34 \pm 0.036$ & $12.66 \pm 0.378$ & $8.80 \pm 0.642$ & $12.51 \pm 0.380$ & $13.34 \pm 0.291$ \\
\hline Hausner's ratio & $1.157 \pm 0.005$ & $1.127 \pm 0.001$ & $1.149 \pm 0.005$ & $1.098 \pm 0.005$ & $1.135 \pm 0.005$ & $1.153 \pm 0.003$ \\
\hline Angle of repose $(\theta)$ & $25^{\circ} .62^{\prime} \pm 0.503$ & $26^{\circ} .68^{\prime} \pm 0.450$ & $29^{\circ} .17^{\prime} \pm 0.166$ & $32^{\circ} .31^{\prime} \pm 0.254$ & $30^{\circ} .00^{\prime} \pm 0.950$ & $24^{\circ} .04^{\prime} \pm 0.044$ \\
\hline Porosity (\%) & $16.03 \pm 0.352$ & $11.30 \pm 0.050$ & $13.12 \pm 0.282$ & $9.14 \pm 0.533$ & $12.17 \pm 0.700$ & $13.27 \pm 0.289$ \\
\hline
\end{tabular}

Mean $\pm S D,(n=3)$

\section{Post compression parameters}

Post compression evaluation parameters of all formulations (F1-F6) were carried successfully and data are tabulated in Table 8.

Table 8: Post Compression studies of different formulations

\begin{tabular}{|c|c|c|c|c|c|c|}
\hline \multirow[b]{2}{*}{ Parameters } & \multicolumn{6}{|c|}{ Formulation code } \\
\hline & F1 & F2 & F3 & F4 & F5 & F6 \\
\hline Hardness $\left(\mathrm{kg} / \mathrm{cm}^{2}\right)$ & $3.10 \pm 0.100$ & $2.83 \pm 0.050$ & $2.60 \pm 0.100$ & $3.23 \pm 0.010$ & $2.46 \pm 0.020$ & $2.53 \pm 0.018$ \\
\hline Thickness(mm) & $2.77 \pm 0.020$ & $3.06 \pm 0.000$ & $3.05 \pm 0.005$ & $2.95 \pm 0.002$ & $3.04 \pm 0.002$ & $3.05 \pm 0.000$ \\
\hline Diameter (mm) & $7.75 \pm 0.005$ & $8.10 \pm 0.000$ & $8.31 \pm 0.000$ & $8.21 \pm 0.001$ & $8.09 \pm 0.000$ & $7.88 \pm 0.003$ \\
\hline Friability (\%) & $0.31 \pm 0.030$ & $0.46 \pm 0.013$ & $0.53 \pm 0.032$ & $0.55 \pm 0.030$ & $0.35 \pm 0.058$ & $0.25 \pm 0.032$ \\
\hline Weight variation (mg) & $170.6 \pm 0.785$ & $169.7 \pm 0.457$ & $170.4 \pm 0.152$ & $170.6 \pm 0.451$ & $170.4 \pm 0.754$ & $170.1 \pm 0.321$ \\
\hline $\begin{array}{l}\text { \%Drug content } \\
\text { (Pioglitazone) }\end{array}$ & $98.34 \pm 0.410$ & $98.66 \pm 0.305$ & $97.52 \pm 0.163$ & $98.96 \pm 0.081$ & $99.46 \pm 0.152$ & $97.53 \pm 0.831$ \\
\hline $\begin{array}{l}\text { \%Drug content } \\
\text { (Cilnidipine) }\end{array}$ & $95.88 \pm 0.915$ & $95.06 \pm 0.163$ & $96.86 \pm 0.751$ & $93.56 \pm 0.444$ & $93.62 \pm 0.294$ & $95.25 \pm 0.012$ \\
\hline $\begin{array}{c}\text { In-vitro disintegration } \\
\text { time (sec.) }\end{array}$ & $59.7 \pm 2.081$ & $42.6 \pm 1.154$ & $39.3 \pm 1.258$ & $80.0 \pm 2.025$ & $18.5 \pm 0.950$ & $22.6 \pm 2.259$ \\
\hline
\end{tabular}




\section{In vitro dissolution studies}

The determination of drug release was done for all formulations using different polymers in the different ratio.
Among all the six formulations, F5 showed the highest percentage drug release of Pioglitazone and medium release of Cilnidipine. The in vitro drug release of Pioglitazone and Cilnidipine in different formulations was shown in Figure 6.
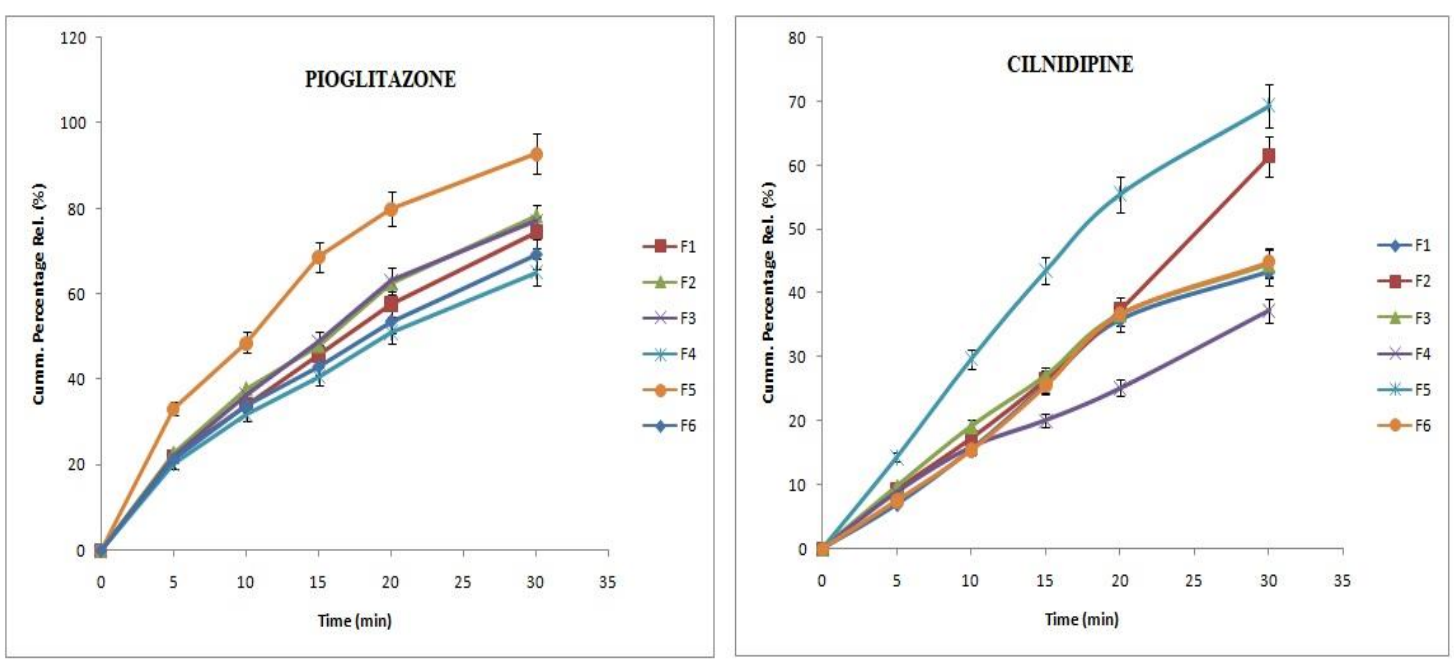

Figure 6: In vitro drug release studies for F1-F6 formulations

\section{Mathematical models for drug release studies}

For studying the various mathematical model, DDSolver software was used. The values of various curve fitting data of in vitro profiles of various formulations are shown in Table 9 \&10.

In Weibull release kinetic modeling of Pioglitazone, the mean $\mathrm{R}^{2}$ value for all formulations was found to be 0.999 , whereas, Ti value for all formulations was found to be 0.000 , indicating there was no lag time for the dissolution of the drug. In Weibull release kinetic modeling of Cilnidipine, the mean $\mathrm{R}^{2}$ value for all formulations was found to be 0.997 , whereas, Ti value for all formulations was found to be in the range of $0.000-0.304$, where, F1 showed the maximum value of 0.304 and F2, F4 and F5 showed the minimum value of
0.000 , indicating there was no lag time for the dissolution of the drug in F2, F4 and F5 and F1 indicating the lag time value of 0.304 . Korsmeyer-Peppas $\mathrm{n}$ value varied from $0.355-1.130$, in which $\mathrm{F} 1$ showed the maximum value of 1.130 and F5 showed the minimum value of 0.355 . Korsmeyer-Peppas $\mathrm{n}<0.5$ for $\mathrm{F} 2-\mathrm{F} 6$ showed that the release of Pioglitazone from fast dissolving tablets followed fickian diffusion mechanism. The mean $\mathrm{R}^{2}$ square value for all formulation was found to be 0.981 . Korsmeyer-Peppas $n$ value varied from $0.388-0.880$, in which F1 showed the maximum value of 0.880 and $F 5$ showed the minimum value of 0.388 . Korsmeyer-Peppas $\mathrm{n}<0.5$ for $\mathrm{F} 5$ showed that the release of Cilnidipine from fast dissolving tablets followed fickian diffusion mechanism. The mean $\mathrm{R}^{2}$ value for formulation found to be 0.998 .

Table 9: Fit of different kinetic models for release of Pioglitazone formulations

\begin{tabular}{|c|c|c|c|c|c|c|c|c|}
\hline \multirow[t]{2}{*}{ Kinetics model } & \multicolumn{6}{|c|}{ K value } & \multirow[t]{2}{*}{ S.D } & \multirow[t]{2}{*}{ RSD\% } \\
\hline & F1 & F2 & F3 & F4 & F5 & F6 & & \\
\hline Zero order & 2.74 & 2.91 & 2.89 & 2.42 & 3.67 & 2.569 & 0.438 & 15.27 \\
\hline First order & 0.001 & 0.001 & 0.001 & 0.001 & 0.001 & 0.001 & 0 & 8.88 \\
\hline Higuchi model & 24.95 & 26.56 & 26.36 & 22.20 & 34.28 & 23.52 & 4.223 & 16.05 \\
\hline Weibull model $(\alpha)$ & 56.34 & 54.48 & 54.84 & 56.76 & 50.80 & 55.95 & 2.075 & 3.79 \\
\hline Weibull model $(\beta)$ & 0.396 & 0.390 & 0.402 & 0.386 & 0.317 & 0.376 & 0.031 & 8.19 \\
\hline $\begin{array}{c}\text { Korsmeyer-peppas } \\
\text { model }\end{array}$ & 1.587 & 1.584 & 1.575 & 1.573 & 1.721 & 1.536 & 0.072 & 4.55 \\
\hline
\end{tabular}


Table 10: Fit of different kinetic models for release of Cilnidipine formulations

\begin{tabular}{|c|c|c|c|c|c|c|c|c|}
\hline \multirow[t]{2}{*}{ Kinetics model } & \multicolumn{6}{|c|}{ K value } & \multirow[t]{2}{*}{ S.D } & \multirow[t]{2}{*}{ RSD\% } \\
\hline & F1 & F2 & F3 & F4 & F5 & F6 & & \\
\hline Zero order & 1.57 & 1.94 & 1.64 & 1.28 & 2.58 & 1.60 & 0.449 & 25.30 \\
\hline First order & 0.001 & 0.001 & 0.001 & 0.001 & 0.001 & 0.001 & 0 & 7.06 \\
\hline Higuchi model & 13.82 & 16.31 & 14.77 & 11.53 & 23.71 & 14.20 & 4.227 & 26.80 \\
\hline Weibull model $(\alpha)$ & 56.74 & 66.19 & 59.65 & 69.65 & 55.49 & 64.20 & 5.604 & 9.042 \\
\hline Weibull model $(\beta)$ & 0.523 & 0.719 & 0.479 & 0.565 & 0.340 & 0.668 & 0.136 & 24.80 \\
\hline $\begin{array}{c}\text { Korsmeyer-peppas } \\
\text { model }\end{array}$ & 1.195 & 1.264 & 1.282 & 1.192 & 1.555 & 1.212 & 0.138 & 10.76 \\
\hline
\end{tabular}

\section{Stability studies}

The optimized final formulation F5 was selected based on the results of in-vitro disintegration time, and in-vitro dissolution studies. The formulation was kept in stability chamber at temperature $40 \pm 1^{\circ} \mathrm{c}$ and Relative humidity
$75 \% \pm 5 \%$ for 2 months. Formulation F5 showed no change in color, indicating no changes in appearance of tablets. Further, hardness, friability, in vitro disintegration and in vitro dissolution studies were performed and results were shown in Table 11.

Table 11: Stability data of F5 formulation

\begin{tabular}{|c|c|}
\hline Parameters & F5 \\
\hline General appearance & No change \\
\hline Hardness (kg/cm ${ }^{2}$ ) & $2.43 \pm 0.005$ \\
\hline Friability (\%) & $0.55 \pm 0.049$ \\
\hline In-vitro disintegration time(sec.) & $18.10 \pm 0.763$ \\
\hline In vitro dissolution(after 30 min) & $90.80 \pm 0.001$ (For Pioglitazone) \\
& $66.40 \pm 0.003$ (For Cilnidipine) \\
\hline
\end{tabular}

Mean \pm SD, $(n=3)$

\section{CONCLUSION}

Fast dissolving tablets of Pioglitazone and Cilnidipine were manufactured using direct compression method for the treatment of diabetic induced hypertension. In the manufacturing of tablets, I was also used as natural superdisintegrant. The tablets were prepared successfully and shown promising in vitro results which could further enhance the efficacy of the formulation by improving onset of action bioavailability of the drugs. Further apart from super disintegrant nature of Opuntia ficus indica, it can show synergistic therapeutic action when given in combined form.

\section{ACKNOWLEDGMENTS}

Authors are thankful to Dr. Ran Singh, Managing Director and Dr. M S Ashawat, Principal, Laureate Institute of Pharmacy for providing the facilities to conduct this research.

\section{CONFLICT OF INTEREST: None declared.}

\section{REFERENCES}

1. Kaveeshwar AS, Cornwall J, the current state of diabetes mellitus in India, Australas Med J. 2014; 7(1):45-48.

2. Geldsetzer P, Manne-Goehler J, Theilmann M, Davies JI, Awasthi A, Vollmer S, Jaacks LM, Bärnighausen T, Atun R Diabetes and Hypertension in India: A Nationally Representative Study of 1.3 Million Adults. JAMA Intern Med. 2018; 178(3):363-372.
3. Mattson JS, Cerutis DR, Diabetes mellitus: a review of the literature and dental implications, Compend Contin Educ Dent. 2001; 22(9):757-60, 762, 764.

4. https://en.wikipedia.org/wiki/Pioglitazone.

5. https://en.wikipedia.org/wiki/Cilnidipine.

6. Masih A, Kumar A, Singh S, Tiwari A, Fast dissolving tablets: A review, School of pharmaceutical sciences, Jaipur National University, Jaipur, Rajasthan, 2017; 9(2).

7. Siddiqui N, Garg G, Sharma P, "Fast dissolving tablets: preparation, charcaterisation and evaluation: an overview." Int J. Pharm.Sci. Res. 2010; 4(2):87-95

8. Hugo J, Nutritional composition of the Prickly pear (Opuntia ficusindica), Nutritional composition of fruit cultivars, Academic Press, 691-712.

9. Ahad H.A, Sreenivasulu R, Reddy B, Kavitha K, Sumapadmaja B, Isolation and Characterization of Ficus indica fruit mucilage, Journal of Pharmacy Research, 2011; 4(3):726-727.

10. Pavia D.L, Gary M.L, James A, George S. Ultraviolet spectroscopy, Introduction to spectroscopy, 4th ed. Cengage learning; 2009. P. 381-417.

11. Safila N, Zehra A, Tasleem M, Assay of Pioglitazone HCl by using UV Visible spectrophotometer, British Journal of Research.

12. Sharma Y.R, Introduction to UV Visible spectroscopy. Elemental organic spectroscopy. $4^{\text {th }}$ ed. S. Chand Publisher; 1980. P. 69190.

13. Ashford M. Assessment of biopharmaceutical properties. In: Aulton ME. Aulton's pharmaceutics the design and manufacture of medicines. 3rd ed. London. Harcourt Publishers Limited; 2007. P. 304-322.

14. Patel A, Panchal A, Patel V, Nagar A. "FTIR spectroscopic method for quantitative analysis of Cilnidipine in tablet dosage form" International Journal Of Pharma Sciences and Research, 2015; $4(6)$. 
15. Farouk F, Moussa BA, Azzazy H.M.E. Fourier transform infrared spectroscopy for in process inspection, counterfeit detection and quality control of anti- diabetic drugs. Spectroscopy 2011; 26:297-309.

16. Lima de Assis A.C, Alves L, Malheiro J, Barros A.R.A, Opuntia ficus-indica L. Miller (Palma Forrageira) as an Alternative Source of Cellulose for Production of Pharmaceutical Dosage Forms and Biomaterials: Extraction and Characterization, Polymers 2019; 11:1124.

17. Lachman L, Liberman HA and Kang JL. The theory and practice of industrial pharmacy. $3^{\text {rd }} \mathrm{ed}$. Mumbai: Varghese publication house; 1986. P. 293-345.

18. Mohamed EA, Hammid SNA. Formulation and evaluation Pioglitazone tablets. Int. J. PharmSci.2013; 2(2):339-346.

19. Sharma D, Formulation Development and Evaluation of Fast Disintegrating Tablets of Salbutamol Sulphate for Respiratory Disorders, International Scholarly Research Notices , 2013: 8.
20. Venkateswarlu K, Jami KP. Formulation development and in vitro evaluation of mouth dissolving tablets of Pioglitazone hydrochloride; Pharma Tutor. 2016; 4(12):37-42.

21. Mohan A, Gundamaraju R, In vitro and in vivo evaluation of fastdissolving tablets containing solid dispersion of lamotrigine, Int J Pharm Investig. 2015; 5(1):57-64.

22. Prashant, A.B., Taware, G.V., Hariprasanna, R.C., and Najmuddin, M. Development and evaluation of mucoadhesive buccal tablets of loratadine. Journal of Pharmacy Research, 2011; 4:26992702.

23. Siepmann F, Mathematical modeling of drug dissolution, International Journal of Pharmaceutics, 2013; 453(1):12-24.

24. Shaikh H.K, Kshirsagar R.V, Pati S.G, Mathematical Models For Drug Release Characterization: A Review, World journal of pharmacy and pharmaceutical sciences 2014; 3(5):472-80.

25. Patel Z.K, Patel M, Patel R.R, A Review: Formulation of Fast Dissolving Tablet, Pharmatutor Magazine; 2(3):1-17. 